\title{
Hydrogen Gas Is Involved in Auxin-Induced Lateral Root Formation by Modulating Nitric Oxide Synthesis
}

\author{
Zeyu Cao ${ }^{1,+}$, Xingliang Duan ${ }^{1,+}{ }^{\text {, Ping Yao }}{ }^{1}$, Weiti Cui ${ }^{1}$, Dan Cheng ${ }^{1}$, Jing Zhang ${ }^{1}$, \\ Qijiang Jin ${ }^{1}$, Jun Chen ${ }^{2}$, Tianshan Dai ${ }^{3}$ and Wenbiao Shen ${ }^{1, *}$ \\ 1 College of Life Sciences, Laboratory Center of Life Sciences, Nanjing Agricultural University, \\ Nanjing 210095, China; 2017116113@njau.edu.cn (Z.C.); 2016216026@njau.edu.cn (X.D.); \\ 2016116112@njau.edu.cn (P.Y.); wtcui@njau.edu.cn (W.C.); softcheng@njau.edu.cn (D.C.); \\ zhangjingjhc@sjtu.edu.cn (J.Z.); jqj@njau.edu.cn (Q.J.) \\ 2 Wuhan Shizhen Water Structure Research Institute Co., Ltd., Wuhan 430200, China; chenjun@shizhensss.com \\ 3 Xinjiang Hongsheng Kangtong Biotechnology Co., Ltd., Xinjiang 830022, China; tsdai@shizhensss.com \\ * Correspondence: wbshenh@njau.edu.cn; Tel./Fax: +86-25-84-396-542 \\ + These authors contributed equally to this work.
}

Received: 4 September 2017; Accepted: 29 September 2017; Published: 3 October 2017

\begin{abstract}
Metabolism of molecular hydrogen $\left(\mathrm{H}_{2}\right)$ in bacteria and algae has been widely studied, and it has attracted increasing attention in the context of animals and plants. However, the role of endogenous $\mathrm{H}_{2}$ in lateral root (LR) formation is still unclear. Here, our results showed that $\mathrm{H}_{2}$-induced lateral root formation is a universal event. Naphthalene-1-acetic acid (NAA; the auxin analog) was able to trigger endogenous $\mathrm{H}_{2}$ production in tomato seedlings, and a contrasting response was observed in the presence of $N$-1-naphthyphthalamic acid (NPA), an auxin transport inhibitor. NPA-triggered the inhibition of $\mathrm{H}_{2}$ production and thereafter lateral root development was rescued by exogenously applied $\mathrm{H}_{2}$. Detection of endogenous nitric oxide (NO) by the specific probe 4-amino-5-methylamino-2' , $^{\prime}$-difluorofluorescein diacetate (DAF-FM DA) and electron paramagnetic resonance (EPR) analyses revealed that the NO level was increased in both NAA- and $\mathrm{H}_{2}$-treated tomato seedlings. Furthermore, NO production and thereafter LR formation induced by auxin and $\mathrm{H}_{2}$ were prevented by 2-4-carboxyphenyl-4,4,5,5-tetramethylimidazoline-1-oxyl-3-oxide (cPTIO; a specific scavenger of $\mathrm{NO}$ ) and the inhibitor of nitrate reductase (NR; an important NO synthetic enzyme). Molecular evidence confirmed that some representative NO-targeted cell cycle regulatory genes were also induced by $\mathrm{H}_{2}$, but was impaired by the removal of endogenous NO. Genetic evidence suggested that in the presence of $\mathrm{H}_{2}$, Arabidopsis mutants nia2 (in particular) and nia1 (two nitrate reductases (NR)-defective mutants) exhibited defects in lateral root length. Together, these results demonstrated that auxin-induced $\mathrm{H}_{2}$ production was associated with lateral root formation, at least partially via a NR-dependent NO synthesis.
\end{abstract}

Keywords: $\mathrm{H}_{2}$; auxin; lateral root formation; $\mathrm{NO}$; nitrate reductase

\section{Introduction}

In higher plants, the formation of lateral root (LR) is influenced by phytohormones and a wide range of environmental cues, including water availability, nutrients, and abiotic stress [1-3]. Previous studies suggested that auxin regulates and coordinates both lateral root founder cell divisions and polarity during lateral root initiation [3,4]. Genetic and molecular evidence suggested that auxin modulates several cell cycle regulatory genes responsible for lateral root formation, such as CYCA2;1, CYCA3;1, CYCD3;1, CDKA1, and KRP2 in Arabidopsis [1,5]. However, N-1-naphthylphthalamic 
acid (NPA), an effective blocker of auxin polar transport, significantly blocked auxin-induced lateral root development [6]. Ample evidence further revealed that nitric oxide (NO) is a ubiquitous and free radical gas that regulates a wide range of physiological processes in plants, and the important roles of NO in auxin-triggered lateral root formation [7], root hair development [8], and adventitious rooting [9], were discovered. Despite these discoveries, the understanding of the mechanisms of NO biosynthesis in plants is still incomplete. So far, two enzymes mainly involved in NO production were suggested, after the experiments with the inhibitor tests by the removal of endogenous $\mathrm{NO}$, including the application of tungstate (a nitrate reductase (NR) inhibitor) and $N^{\mathrm{G}}$-nitro-L-arginine methyl ester (a nitric oxide synthetase (NOS)-like protein inhibitor) [10,11].

Hydrogen gas $\left(\mathrm{H}_{2}\right)$ is the lightest and most affluent element in the world, constituting about $75 \%$ of universe's elemental mass. The metabolism of $\mathrm{H}_{2}$ by bacteria, green algae, and higher plants, has been reported for many years [12]. Previous studies discovered that $\mathrm{H}_{2}$ is a possible anti-oxidant and anti-inflammatory agent with promising application in clinical treatment $[13,14]$. For instance, $\mathrm{H}_{2}$-rich saline protected lung tissue against injury caused by hypertoxic exposure in rats [15]. Similar to the beneficial roles in animals, $\mathrm{H}_{2}$ has emerged as an important gaseous molecule under abiotic stress and several physiological processes in plants. For example, $\mathrm{H}_{2}$ alleviated Al-induced inhibition of alfalfa root elongation by decreasing NO production in alfalfa seedlings [16]. The involvement of $\mathrm{H}_{2}$ in the promotion of cucumber adventitious root formation was also discovered [17]. Although $\mathrm{H}_{2}$ and $\mathrm{NO}$ were respectively suggested to be required for root architecture, the potential interaction between $\mathrm{H}_{2}$ and $\mathrm{NO}$ during lateral formation is unclear.

To answer this scientific question, we found herein that $\mathrm{H}_{2}$ is involved in auxin-induced lateral root development in tomato seedlings, mimicking the responses of exogenously applied 1-naphthylacetic acid (NAA; the auxin analog). Auxin-induced $\mathrm{H}_{2}$ production is a very interesting observation. Molecular and pharmacological approaches further revealed that $\mathrm{NO}$ may operate downstream of $\mathrm{H}_{2}$ promoting lateral root formation by the modulation of cell cycle regulatory genes. By using the genetic and pharmacological approaches, our results indicated the role of nitrate reductase (NR) in $\mathrm{H}_{2}$-induced Arabidopsis lateral root formation. Our results contribute new insight to our understanding auxin and NO signaling governing root organogenesis in plants.

\section{Results}

\subsection{Exogenous Hydrogen Gas $\left(\mathrm{H}_{2}\right)$-Induced Lateral Root Formation in A Dose-Dependent Manner}

To verify whether $\mathrm{H}_{2}$ had any effects on the lateral root formation in plants, tomato seedlings were incubated with solutions containing different concentrations of exogenous $\mathrm{H}_{2}(0.0078,0.078,0.39$, and $0.78 \mathrm{mM}$ ). Compared to the control samples, treatment with exogenous $\mathrm{H}_{2}$ induced lateral root formation in a dose-dependent fashion, with a maximal effect in $0.39 \mathrm{mM} \mathrm{H}_{2}$ (Figure 1a). For example, it was observed that compared to the control samples, the application of $0.39 \mathrm{mM} \mathrm{H}_{2}$ was able to increase lateral root number, length, and primordial number in tomato seedlings by $119 \%, 273 \%$, and $170 \%$, respectively (Table 1). Thus, $0.39 \mathrm{mM} \mathrm{H}_{2}$ was subsequently used in tomato seedlings.

Similar inducing tendencies were observed in different plant species, including Brassica napus, Brassica chinensis, Oryza sativa, and Zea mays after treatments with $\mathrm{H}_{2}$, and we chose the suitable culture conditions and treated times in the above experiments, for the maximum effect. Therefore, these results revealed that exogenous $\mathrm{H}_{2}$-induced lateral root formation is a universal event.

Three-day-old tomato (Lycopersicon esculentum) seedlings, 2-day-old rapeseed (Brassica napus) seedlings, 3-day-old Chinese cabbage (Brassica chinensis), 4-day-old rice (Oryza sativa) seedlings, and 7-day-old maize (Zea mays) seedlings, were incubated with solutions containing the indicated concentrations of $\mathrm{H}_{2}$ for 3, 3, 2, 2 and 1 days. Afterwards, the number of emerged LRs (>1 mm) per seedling and LR length were analyzed. Meanwhile, the number of emerged LRP was also calculated after treatments for 1, 1, 1, 2 days and $6 \mathrm{~h}$, respectively. Distilled water was used for the control (Con) treatment. Mean and SE values were calculated from at least three independent experiments with 
at least three replicates for each $(n=50)$. Within each set of experiments, dates with asterisks were significantly different with respect to the control at $p<0.05$ according to $t$-test.

Table 1. Exogenous $\mathrm{H}_{2}$-induced lateral root formation is universal.

\begin{tabular}{|c|c|c|c|c|}
\hline Species & Treatment & $\begin{array}{l}\text { LR Number } \\
\text { (seedling }^{-1} \text { ) }\end{array}$ & $\begin{array}{c}\text { LR Length } \\
\left(\mathrm{mm}^{-1} \text { seedling }\right.\end{array}$ & $\begin{array}{l}\begin{array}{l}\text { LRP Number } \\
\text { (seedling }^{-1} \text { ) }\end{array}\end{array}$ \\
\hline \multirow{2}{*}{$\begin{array}{l}\text { Lycopersicon } \\
\text { esculentum }\end{array}$} & Con & $1.89 \pm 0.17$ & $4.03 \pm 0.48$ & $1.25 \pm 0.25$ \\
\hline & $0.39 \mathrm{mM} \mathrm{H}_{2}$ & $4.13 \pm 0.26^{*}$ & $15.03 \pm 1.30 *$ & $3.38 \pm 0.20 *$ \\
\hline \multirow{2}{*}{ Brassica napus } & Con & $1.67 \pm 0.38$ & $4.00 \pm 0.31$ & $1.30 \pm 0.11$ \\
\hline & $0.39 \mathrm{mM} \mathrm{H}_{2}$ & $4.00 \pm 0.26^{*}$ & $15.00 \pm 0.51 *$ & $3.48 \pm 0.20 *$ \\
\hline \multirow[b]{2}{*}{ Brassica chinensis } & Con & $1.74 \pm 0.19$ & $4.21 \pm 0.43$ & $2.17 \pm 0.39$ \\
\hline & $0.078 \mathrm{mM} \mathrm{H}_{2}$ & $5.14 \pm 0.28 *$ & $16.62 \pm 1.23 *$ & $3.58 \pm 0.12 *$ \\
\hline \multirow{2}{*}{ Oryza sativa } & Con & $5.60 \pm 1.18$ & $13.00 \pm 2.74$ & $1.50 \pm 0.24$ \\
\hline & $0.39 \mathrm{mM} \mathrm{H}_{2}$ & $12.05 \pm 1.31$ * & $38.50 \pm 4.78^{*}$ & $2.92 \pm 0.23 *$ \\
\hline \multirow{2}{*}{ Zea mays } & Con & $16.67 \pm 1.62$ & $40.00 \pm 3.85$ & $15.73 \pm 0.52$ \\
\hline & $0.78 \mathrm{mM} \mathrm{H}_{2}$ & $32.41 \pm 1.03$ & $89.60 \pm 2.48 *$ & $35.33 \pm 2.00 *$ \\
\hline
\end{tabular}

Con: Control; LR: Lateral root; LRP: Lateral root primordia. Within each set of experiments, Asterisk indicates that mean values are significantly different at the $\mathrm{p}<0.05$ level according to Duncan's multiple range test.

\subsection{A Possible Link between Auxin and $\mathrm{H}_{2}$ in the Induction of Lateral Root Formation}

It is well-known that exogenous auxin, including 1-naphthylacetic acid (NAA), could increase lateral root development [5,7]. To investigate the link between auxin and $\mathrm{H}_{2}$ in the induction of lateral rooting, 3-day-old tomato seedlings were treated with various concentrations of NAA, $\mathrm{N}$-1-naphthylphthalamic acid (NPA; the auxin transport inhibitor), and $\mathrm{H}_{2}$. As expected, compared to the control, NAA dose-dependently increased the lateral root number and length, with a maximal response at $200 \mathrm{nM}$ NAA (except $2000 \mathrm{nM}$; Figure 1a). However, NPA, the auxin transport blocker, obviously suppressed lateral root organogenesis in a dose-dependent manner as well.

Meanwhile, $\mathrm{H}_{2}$ level in tomato seedling roots was detected by gas chromatography (GC). Comparatively, endogenous $\mathrm{H}_{2}$ production was maximally induced by $200 \mathrm{nM}$ NAA and $0.39 \mathrm{mM}$ $\mathrm{H}_{2}$ supplementation for $6 \mathrm{~h}$ (Figure $1 \mathrm{~b}, \mathrm{c}$ ). Contrasting responses were observed when NPA was exogenously applied. For example, after treatment with $500 \mathrm{nM} \mathrm{NPA}$ for $6 \mathrm{~h}, \mathrm{H}_{2}$ production was obviously reduced by about $52 \%$. Combined with the changes in lateral root formation, these results indicated the possible link between auxin and endogenous $\mathrm{H}_{2}$ in the induction of lateral root formation.

\section{3. $\mathrm{H}_{2}$ Was Partly Involved in Auxin-Induced Lateral Root Formation}

To confirm the above deduction, tomato seedlings were treated with NPA or NAA in the presence or absence of different concentrations of $\mathrm{H}_{2}$. As shown in Figure 2, NPA-inhibited lateral root formation and endogenous $\mathrm{H}_{2}$ production in tomato seedling roots were differentially rescued by the supplement of $0.39 \mathrm{mM} \mathrm{H}_{2}$, but to lesser degrees than those in $0.39 \mathrm{mM} \mathrm{H}_{2}$, or $200 \mathrm{nM}$ NAA-treated alone plants. Meanwhile, additive responses in lateral rooting were observed when NAA was together with $0.39 \mathrm{mM} \mathrm{H}_{2}$ (Figure $\mathrm{S} 1$ ). These results suggested that endogenous $\mathrm{H}_{2}$ might be, at least partially, involved in lateral root formation promoted by auxin. 


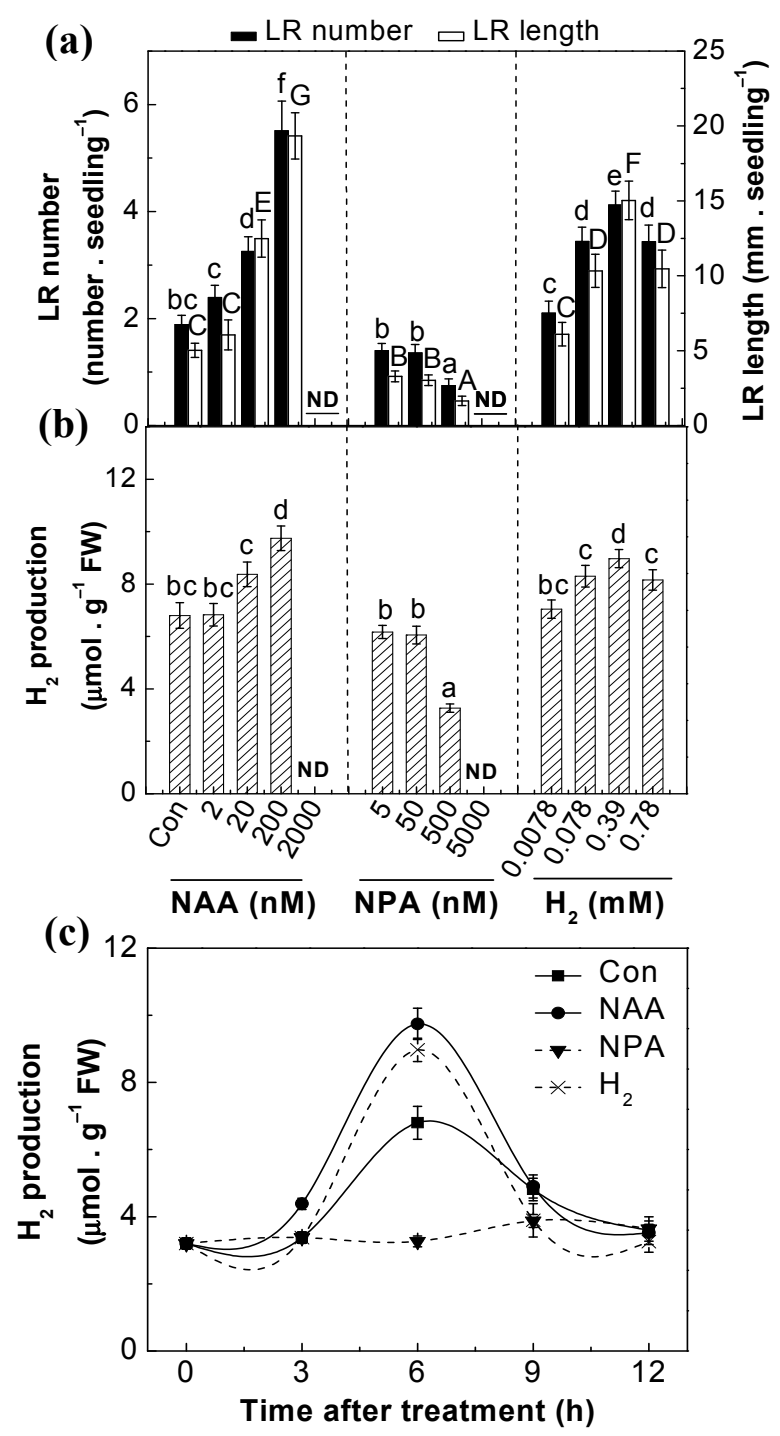

Figure 1. Effects of 1-naphthylacetic acid (NAA), $\mathrm{N}$-1-naphthylphthalamic acid (NPA), and $\mathrm{H}_{2}$ on lateral root formation and $\mathrm{H}_{2}$ release. 3-day-old tomato seedlings were incubated with solutions containing various concentrations of NAA, NPA, and $\mathrm{H}_{2}$. (a) The number of emerged lateral roots (LRs) (>1 mm) per seedling and LR length were calculated after 3-day of treatments $(n=60)$; (b) The $\mathrm{H}_{2}$ production in roots was detected after 6-h treatment $(n=5)$; (c) Time-course of $\mathrm{H}_{2}$ production in response to $200 \mathrm{nM}$ NAA, $500 \mathrm{nM}$ NPA, and $0.39 \mathrm{mM} \mathrm{H}_{2}(n=5)$. Distilled water was used for the control (Con) treatment. Data are the means $\pm \mathrm{SE}$ of three independent experiments with at least three replicates for each. Within each set of experiments, bars denoted by the same letter did not differ significantly at the $p<0.05$ level according to Duncan's multiple range test.

\subsection{Nitric Oxide (NO) Was Involved in $\mathrm{H}_{2}$-Promoted Lateral Root Formation}

The role of $\mathrm{NO}$ in $\mathrm{H}_{2}$-induced lateral root formation was further examined by monitoring root organogenesis and $\mathrm{NO}$ synthesis in response to applied $\mathrm{H}_{2}$ with or without 2-4-carboxyphenyl-4,4,5,5-tetramethylimidazoline-1-oxyl-3-oxide (cPTIO), an effective scavenger of $\mathrm{NO}$. Interestingly, $\mathrm{H}_{2}$ - and NAA-promoted lateral root formation was greatly impaired in the presence of cPTIO (Figure 3a). Meanwhile, endogenous NO was firstly imaged by laser scanning confocal microscopy (LSCM) with the NO indicator dye 4-amino-5-methylamino-2' $7^{\prime}$-difluorofluorescein diacetate (DAF-FM DA). Significant and progressive increases in NO-induced fluorescence were observed in both NAA- and $\mathrm{H}_{2}$-treated tomato seedling roots for $48 \mathrm{~h}$, compared with control (peaking 
at 36 h; Figure 3b,c and Figure S2). Co-treatment with cPTIO reduced the above NO fluorescence. The above changes in fluorescence were further confirmed by using the highly specific electron paramagnetic resonance (EPR) analysis (Figure 3d). Combined with the data from lateral root formation analysis, the above results demonstrated that $\mathrm{NO}$ might act as a downstream component of the complex signaling network inducing lateral root formation triggered by $\mathrm{H}_{2}$.

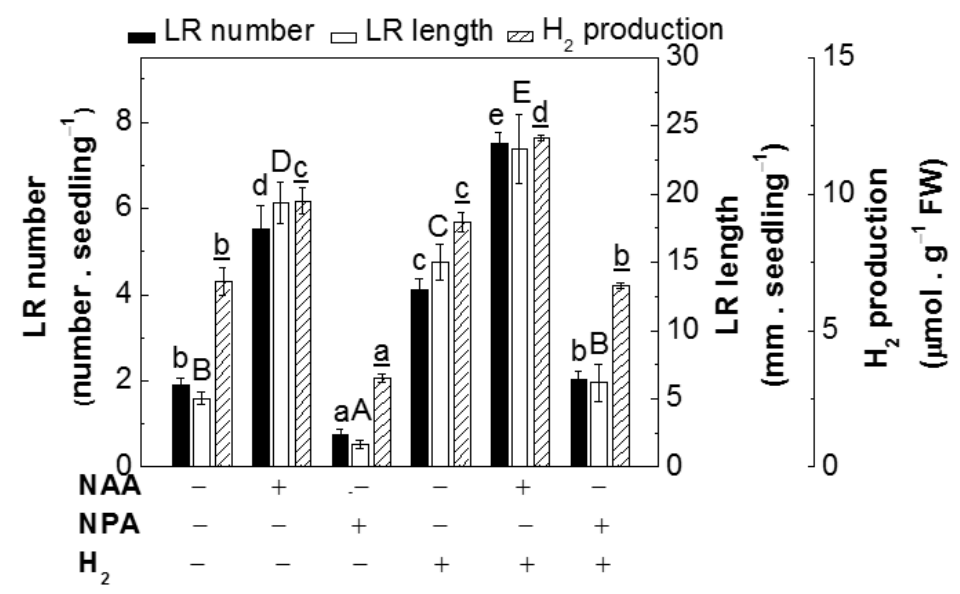

Figure 2. NAA- and NPA-regulated lateral root formation and $\mathrm{H}_{2}$ production were regulated by exogenous $\mathrm{H}_{2}$. 3-day-old tomato seedlings were incubated with solutions containing $200 \mathrm{nM}$ NAA, $500 \mathrm{nM} \mathrm{NPA}$, and $0.39 \mathrm{mM} \mathrm{H}_{2}$, alone or the combination treatments. The number of emerged LRs $(>1 \mathrm{~mm})$ per seedling and LR length were calculated after 3-day of treatment $(n=60)$. The $\mathrm{H}_{2}$ production in roots was determined after 6-h treatment $(n=5)$. Distilled water was used for the control (Con) treatment. Data are the means \pm SE of three independent experiments with at least three replicates for each. Within each set of experiments, bars denoted by the same letter did not differ significantly at the $p<0.05$ level according to Duncan's multiple range test.

\subsection{Nitrate Reductase Might Be the NO Enzymatic Source}

In order to investigate the source(s) of $\mathrm{NO}$ synthesis in $\mathrm{H}_{2}$-induced lateral root formation, the Nitrate reductase (NR) inhibitor tungstate (Tg) and NOS-like protein inhibitors $N^{\mathrm{G}}$-nitro-L-arginine methyl ester (NAME) were respectively used. Subsequent results showed that both NAA- and $\mathrm{H}_{2}$-induced lateral root length and number, and $\mathrm{NR}$ activities were obviously blocked by $\mathrm{Tg}$, while NAME had no such significant effects (Figure 4a,b,d and Figure S3a,b). Consistently, both LSCM and EPR analyses showed that $\mathrm{H}_{2}$-induced $\mathrm{NO}$ production was more sensitive to $\mathrm{Tg}$ (Figure $4 \mathrm{c}, \mathrm{e}$ ). However, there is no significant effect when NAME was applied, at least in our experiments (Figure S3b). Additionally, it is reported that $S$-nitrosoglutathione reductase (GSNOR) can modulate the cellular $\mathrm{NO}$ homeostasis [18]. Thus, the potential effect of $\mathrm{H}_{2}$ on GSNOR activity after $36 \mathrm{~h}$ treatment was studied. We found that $\mathrm{H}_{2}$ caused a slight but not significant increase in GSNOR activity (Figure S3c), indicating that GSNOR might not be the enzymatic source of $\mathrm{NO}$ generation in $\mathrm{H}_{2}$-induced tomato lateral root development. Thereby, our pharmacological and physiological evidence supported that $\mathrm{NR}$ might be the main source of $\mathrm{NO}$ synthesis during $\mathrm{H}_{2}$-induced $\mathrm{NO}$ generation and thereafter lateral root formation. 
(a)

(b)

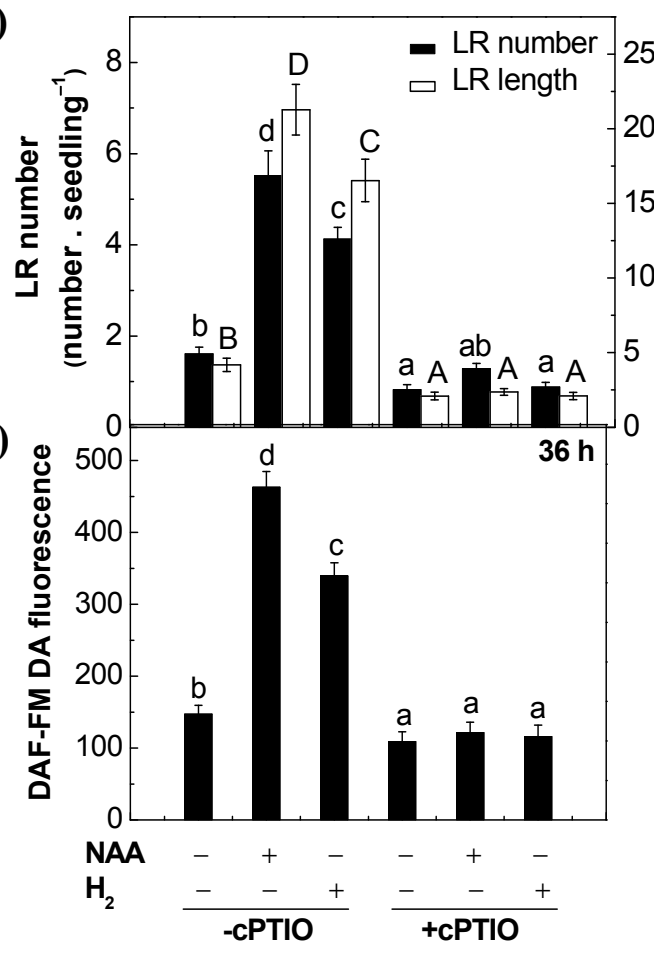

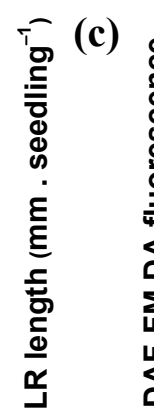

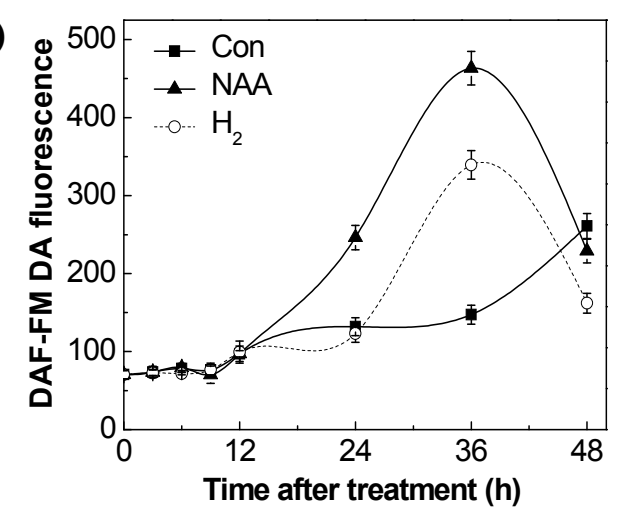

(d)
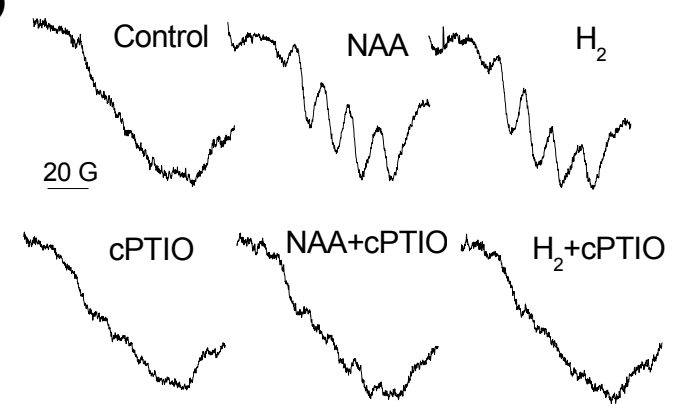

Figure 3. $\mathrm{H}_{2}$-induced nitric oxide $(\mathrm{NO})$ production and lateral rooting were sensitive to the removal of NO by 2-4-carboxyphenyl-4,4,5,5-tetramethylimidazoline-1-oxyl-3-oxide (cPTIO), a NO scavenger. 3-day-old tomato seedlings were incubated with solutions containing $200 \mathrm{nM} \mathrm{NAA}, 0.39 \mathrm{mM} \mathrm{H}_{2}$, and $200 \mu \mathrm{M}$ cPTIO, alone or the combination treatments. (a) The number of emerged LRs $(>1 \mathrm{~mm})$ per seedling and LR length were calculated after 3-day of treatments. Meanwhile, the NO fluorescence in tomato roots was analyzed by fluorescence probe DAF-FM DA at $36 \mathrm{~h}$ (b) and over $48 \mathrm{~h}$; (c) of treatments, respectively, using laser scanning confocal microscopy (LSCM) (TCS-SP2 system; Leica Lasertechnik $\mathrm{GmbH}$ ). The DAF-FM DA fluorescence density was analyzed using Leica software. (d) The NO signal was also detected by electron paramagnetic resonance (EPR) after being treated for $36 \mathrm{~h}$. Distilled water was used for the control (Con) treatment. Data are the means $\pm \mathrm{SE}$ of three independent experiments with at least three replicates for each $(n=60$ for lateral root formation analysis; $n=5$ for NO detection). Within each set of experiments, bars denoted by the same letter did not differ significantly at $p<0.05$ level according to Duncan's multiple range test.

\subsection{NO Participated in $\mathrm{H}_{2}$-Induced Transcript Levels of Cell Cycle Regulatory Genes}

To gain insight into the molecular mechanism of $\mathrm{H}_{2}$-induced lateral root formation, the changes in the expression profiles of cell cycle regulatory genes (NO-targeted gens responsible for lateral root formation; [1,5]), including CDKA1, CYCD3;1, and CYCA2;1, were analyzed by qPCR. As shown in Figure 5, NAA and $\mathrm{H}_{2}$ significantly up-regulated above transcripts, all of which were markedly impaired by the co-treatment with cPTIO or Tg. Our results thus indicated that NR-dependent NO might be involved in $\mathrm{H}_{2}$-induced expression of cell cycle regulatory genes responsible for lateral root formation. 
(a)

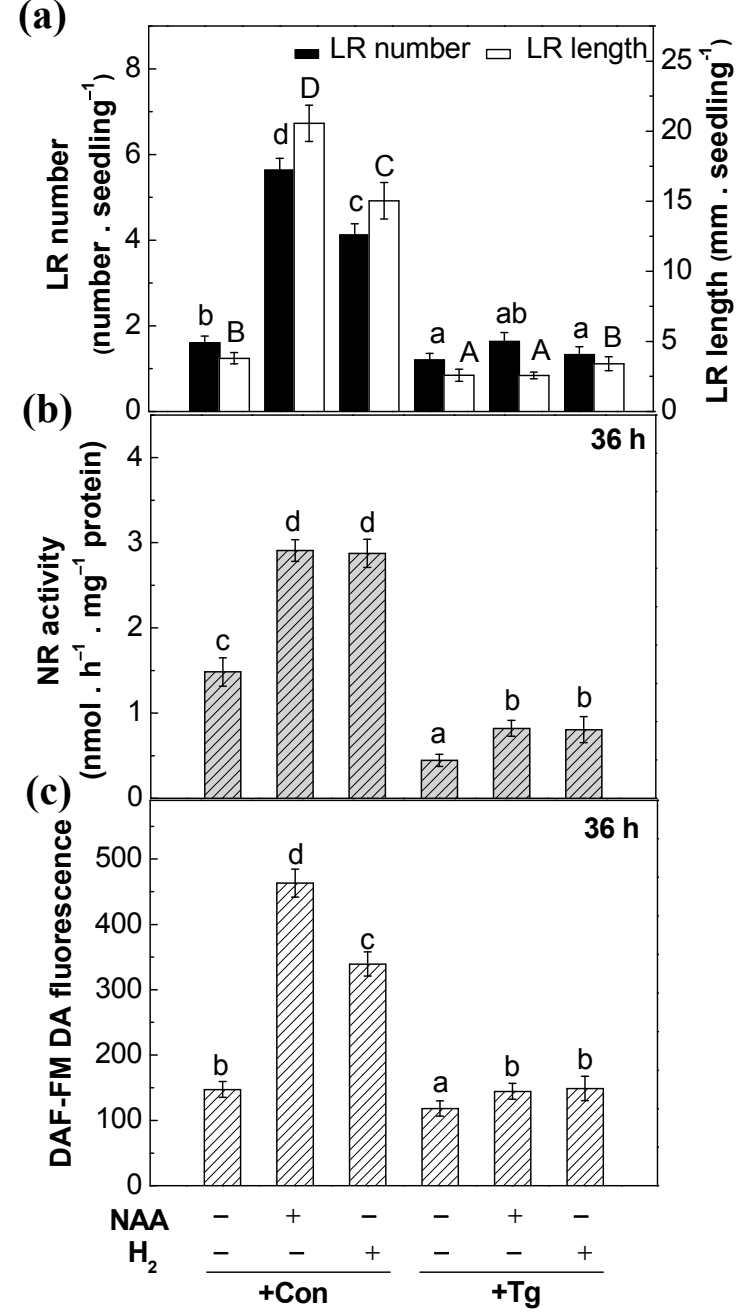

(d)

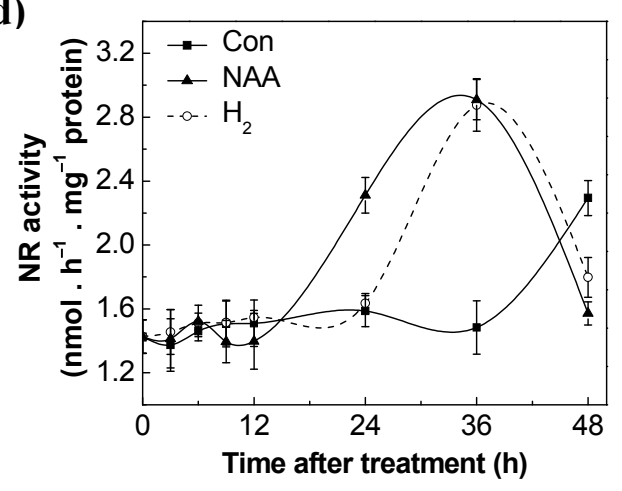

(e)

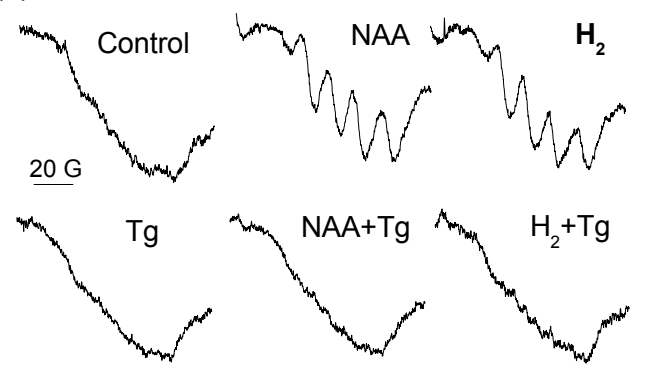

Figure 4. NR might be the enzymatic source of $\mathrm{H}_{2}$-triggered $\mathrm{NO}$ generation. 3-day-old tomato seedlings were incubated with solutions containing $200 \mathrm{nM} \mathrm{NAA}, 0.39 \mathrm{mM} \mathrm{H}_{2}$, and $20 \mu \mathrm{M}$ tungstate $(\mathrm{Tg})$, alone or the combination treatments. (a) The number of emerged LRs $(>1 \mathrm{~mm})$ per seedling and LR length were calculated after 3-day of treatments. Meanwhile, the activity of nitrate reductase (NR) was determined at $36 \mathrm{~h}(\mathbf{b})$ and over $48 \mathrm{~h}(\mathbf{d})$ of treatments, respectively; (c) The NO fluorescence in tomato roots was analyzed by fluorescence probe DAF-FM DA at $36 \mathrm{~h}$ of treatments, using LSCM (TCS-SP2 system; Leica Lasertechnik GmbH). The DAF-FM DA fluorescence density was analyzed using Leica software; (e) The NO signal was also detected by EPR after being treated for $36 \mathrm{~h}$. Distilled water was used for the control (Con) treatment. Data are the means \pm SE of three independent experiments with at least three replicates for each $(n=60$ for lateral root formation analysis; $n=5$ for NR activity and NO detection). Within each set of experiments, bars denoted by the same letter did not differ significantly at $P<0.05$ level according to Duncan's multiple range test.

\subsection{Genetic Evidence Supporting the Role of NR-Derived $N O$ in $\mathrm{H}_{2}$-Induced Lateral Root Formation}

To confirm the role of nitric reductase (NR) in $\mathrm{H}_{2}$-induced lateral root formation, Arabidopsis nitric reductase 1 (nia1) and nitric reductase 2 (nia2) mutants, both of which are impaired in NO synthesis in plants [19], were further used. As shown in Figure 6a,c, in comparison with the wild-type (WT), nia 2 but not nia1 mutant under the normal growth conditions, showed a phenotype of impaired lateral root number. Further results revealed that compared to WT, nia2 (in particularly) and nia1 mutants were less sensitive to exogenously applied $\mathrm{H}_{2}$. The above preliminary genetic evidence supported the idea that NR partially mediates $\mathrm{H}_{2}$-induced lateral root formation, at least in Arabidopsis. 


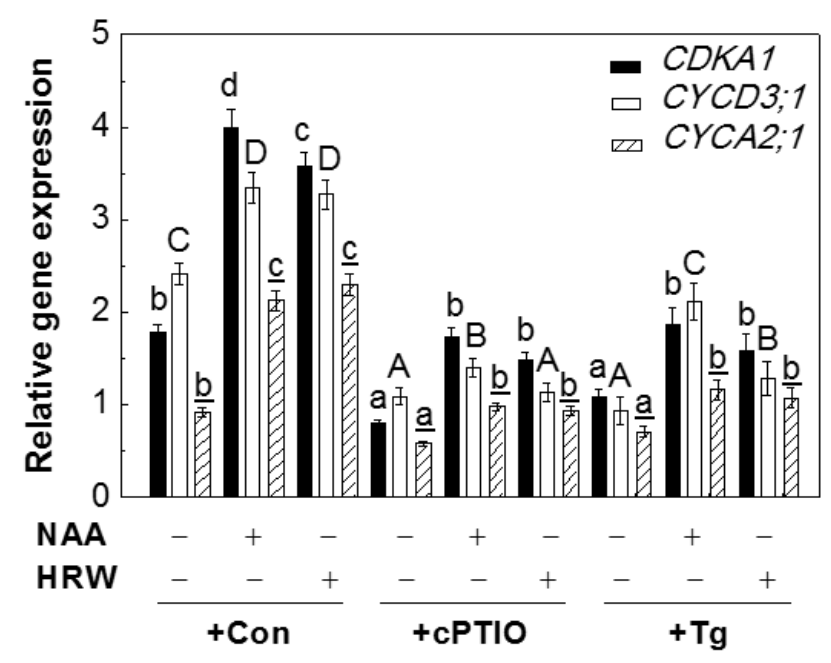

Figure 5. $\mathrm{H}_{2}$-induced cell cycle regulatory gene transcripts were sensitive to the removal of $\mathrm{NO}$ with its scavenger and NR inhibitor. Three-day-old tomato seedlings were incubated with solutions containing $200 \mathrm{nM}$ NAA, $0.39 \mathrm{mM} \mathrm{H}_{2}, 200 \mu \mathrm{M}$ cPTIO, and $20 \mu \mathrm{M}$ tungstate (Tg), alone or the combination treatments for $36 \mathrm{~h}$. The transcripts of tomato CDKA1, CYCD3;1, and CYCA2;1 were analyzed using qPCR. Distilled water was used for the control (Con) treatment. Data are the means \pm SE of three independent experiments with at least three replicates for each. Within each set of experiments, bars denoted by the same letter did not differ significantly at $p<0.05$ level according to Duncan's multiple range test.

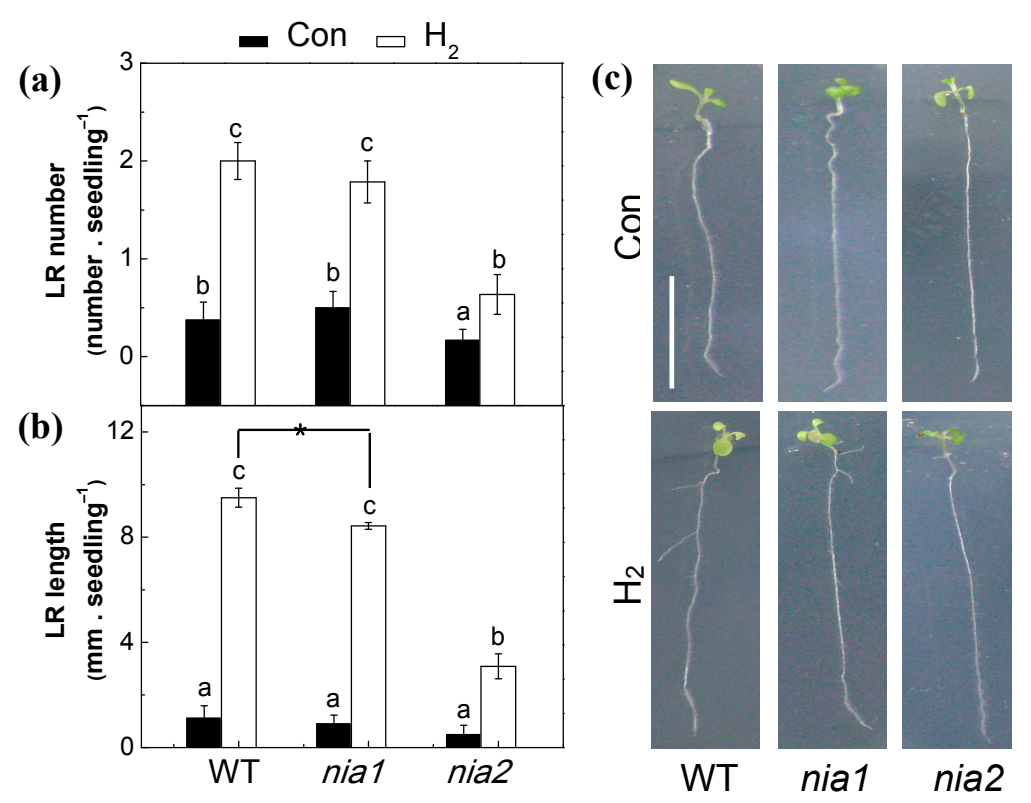

Figure 6. Genetic evidence supporting the involvement of $\mathrm{NR}$ in $\mathrm{H}_{2}$-induced lateral root formation. 7-day-old Arabidopsis seedlings of wild-type (WT), nia1, and nia2 mutants were treated with semi-strength Murashige and Skoog (MS) medium in the presence or absence of $0.078 \mathrm{mM} \mathrm{H}_{2}$. $(\mathbf{a}, \mathbf{b})$ The number of emerged LRs $(>1 \mathrm{~mm})$ per seedling and LR length were calculated after 3-day treatment; (c) Representative photographs were then taken. Bar $=1 \mathrm{~cm}$. Treatment without $\mathrm{H}_{2}$ was regarded as control (Con). Data are the means $\pm \mathrm{SE}$ of three independent experiments with at least three replicates for each $(n=20)$. Within each set of experiments, bars denoted by the same letter or labeled with an asterisk did not differ significantly at $p<0.05$ level according to Duncan's multiple range test. 


\section{Discussion}

Root branching through lateral root formation is an important component of the adaptability of the root system to environment. Although many studies emphasized that the phytohormone auxin acts as a common trigger related to many endogenous and environmental signals governing root organogenesis [1-3], knowledge regarding its downstream components in lateral root formation remains limited. The results presented here showed that auxin-induced $\mathrm{H}_{2}$ production is associated with lateral root formation, and NR-mediated NO, a well-known important gaseous signaling molecule in plants $[20,21]$, was at least partly, required for the $\mathrm{H}_{2}$-triggered lateral root formation promoted by auxin.

This report showed that the increases in endogenous $\mathrm{H}_{2}$ and thereafter $\mathrm{NO}$ production are two responses involved in the signaling transduction pathways elicited by auxin in tomato seedling roots. The concentration of $\mathrm{H}_{2}$ increased by $43 \%$ in tomato seedling roots after $6 \mathrm{~h}$ of auxin administration (Figure 1c). Contrasting response was found in NPA-treated seedlings. In the same period, NO concentration was in the basal level, followed by a progressive increase, thus reaching the peak after $36 \mathrm{~h}$ of treatment (Figures $3 \mathrm{c}$ and S2). We also noticed these two events obviously preceded the beginning of lateral formation. Similar induction in endogenous $\mathrm{H}_{2}$ and $\mathrm{NO}$ production was also observed in ABA-treated Arabidopsis seedlings [22]. This finding is an interesting event, since a $\mathrm{H}_{2}$ increase may have different physiological functions in various experiment systems, when the specific phytohormone(s) was administrated. For example, $\mathrm{H}_{2}$-mediated induction of adventitious rooting is correlated with auxin signaling in cucumber explants [17]. The regulation of phytohormone signaling pathway by $\mathrm{H}_{2}$ was also preliminarily suggested in plants [23]. Additionally, the number and length of lateral roots and the amount of root hair were increased when the seedlings were inoculated with $\mathrm{H}_{2}$-oxidizing bacteria [24].

Subsequent experiments discovered that auxin-induced $\mathrm{H}_{2}$ participates in the promotion of lateral root formation (Figure 1a). This conclusion was supported by the following results. First, the increase or decrease in endogenous $\mathrm{H}_{2}$ production was observed when NAA or NPA (the auxin transport inhibitor; [6,7]) was individually applied in tomato seedlings, both of which were correlated to the phenotypes of lateral root number and length (induction or inhibition, respectively; Figure 1a,b). Second, NPA-inhibited $\mathrm{H}_{2}$ production in vivo and thereafter lateral root formation were obviously alleviated by exogenously applied $0.39 \mathrm{mM} \mathrm{H}_{2}$, a concentration confirmed to be effective in our experimental conditions (Figures 2 and S1).

Previous investigation revealed the physiological roles of $\mathrm{H}_{2}$ against salt stress [25,26], paraquat-induced oxidative stress [27], and metal toxicity in plants [16,28-30]. Interestingly, ABA-triggered $\mathrm{H}_{2}$ production was confirmed to participate in the enhancement of drought tolerance in Arabidopsis seedlings [22]. Accordingly, combined with the induction of adventitious rooting in cucumber explants [17], it was further deduced that $\mathrm{H}_{2}$ is not only an important plant growth regulator against abiotic stress, but also an inducer of root organogenesis in an auxin-dependent fashion, although auxin-independent pathway also exists [31]. Additionally, $\mathrm{H}_{2}$-tgriggered lateral root formation might be a universal event in plants (Table 1).

NO is a signaling molecule involved in many physiological processes during plant development, such as root gravitropism, seed germination, and root organogenesis (including lateral root and adventitious root formation, etc.) [5,7,32-35]. In response to abiotic stress, NR-mediated NO generation in plants has been demonstrated both in vivo and in vitro [36,37], and it was confirmed to be the downstream component responsible for plant tolerance against environmental stimuli [38]. For example, NR-dependent NO could play a pivotal role in improving the nitrogen acquisition capacity by increasing lateral root initiation and the inorganic nitrogen uptake rate under partial nitrate nutrition in rice [39]. R4, isolated from Rhizobium leguminosarum bv. trifolii, did not inhibit rice root growth by completing the reduction of $\mathrm{NO}$ through to nitrogen gas [40]. Our further pharmacological, physiological, and genetic evidence revealed the causal link between endogenous $\mathrm{H}_{2}$ and $\mathrm{NO}$ in the induction of lateral root formation. 
First, we found that both $\mathrm{H}_{2}$ and NAA increased NR activities in tomato seedlings in a time-dependent manner (Figure $4 \mathrm{~d}$ ), and this increased NR activity may account for the induction of endogenous NO levels, which was confirmed by LSCM and ESR analysis (Figures 3c,d and S2). Above increased endogenous NO levels in tomato seedlings, coincident with lateral root formation (Figure 1a), were further reduced by Tg (the NR inhibitor) or CPTIO (the specific scavenger of NO), when applied together with $\mathrm{H}_{2}$ or NAA (Figures $3 b$ and $4 b, c, e$ ). Meanwhile, $\mathrm{H}_{2}$ - and NAA-triggered lateral root formation was respectively blocked by the removal of endogenous NO (Figures 3a and 4a). No such responses were observed when the NOS inhibitor, NAME, was used (Figure S3). The possible involvement of NOS-like protein was thus ruled out. Consistently, the requirement of NO in $\mathrm{H}_{2}$-promoted adventitious rooting was discovered in cucumber explants as well [41], confirming the central role of $\mathrm{NO}$ in root organogenesis. Our previous results revealed that $\mathrm{H}_{2}$-stimulated significant induction of NO synthesis was associated with stomatal closure in the wild type of Arabidopsis, which were individually abolished in NR mutants (nia1/2) [22]. Together, we deduced that the increased endogenous NO levels mainly resulting from the induction of NR activity were likely to account for the promotion of lateral root formation in response to $\mathrm{H}_{2}$. Further data that was subsequently obtained, working with WT and NR mutants of Arabidopsis, provided the genetic evidence to support this conclusion (Figure 6).

It was suggested that auxin-triggered NO-mediated cell cycler reactivation occurred by modulating cell cycle regulatory genes in the early lateral root initiation $[5,42]$. As expected, mimicking the responses of NAA, $\mathrm{H}_{2}$ treatment for $36 \mathrm{~h}$ could up-regulate the expression of CDKA1, CYCD3;1, and CYCA2;1, all of which were abolished by the removal of endogenous NO (Figure 5). Combined with corresponding phenotypes (Figures $3 \mathrm{a}$ and $4 \mathrm{a}$ ), the above molecular evidence suggested that NO-targeted cell cycle regulatory genes might be involved in the induction of lateral root formation prompted by $\mathrm{H}_{2}$.

In conclusion, the above results revealed the involvement of $\mathrm{H}_{2}$ in auxin-induced lateral root formation via NO signaling, and provided new insight regarding the use of $\mathrm{H}_{2}$ in agriculture.

\section{Materials and Methods}

\subsection{Chemicals}

Unless stated otherwise, all chemicals were obtained from Sigma-Aldrich (St Louis, MO, USA). The chemicals of 1-naphthylacetic acid (NAA), N-1-naphthylphthalamic acid (NPA, an inhibitor of auxin transport), 2-(4-carboxyphenyl)-4,4,5,5-tetramethylimidazoline-1-oxyl-3-oxide potassium salt (cPTIO; a scavenger of $\mathrm{NO}$ ), tungstate ( $\mathrm{Tg}$; an inhibitor of $\mathrm{NR}$ ), and $\mathrm{N}^{\mathrm{G}}$-nitro-L-arginine methyl ester hydrochloride (NAME; a NO synthase-like enzyme inhibitor) were applied [7,8,22]. In this study, the concentrations of the above chemicals were determined in pilot experiments from which the significant responses were observed.

\subsection{Plant Materials and Growth Conditions}

Tomato (Lycopersicon esculintum, cv. Jiangshu No. 14), green vegetables (Brassica chinensis, cv. Wuqing No. 1), and rice (Oryza sativa, cv. Wuyujing No. 7) were obtained from Jiangsu Academy of Agricultural Sciences. Maize (Zea mays, Zhongnuo No. 1) was provided by Chinese Agricultural University. Rapeseed (Brassica napus cv. Yangyou No. 6) seeds were kindly supplied by State Key Laboratory of Crop Genetics and Germplasm Enhancement, Nanjing Agricultural University. Seeds were surface-sterilized with $2 \% \mathrm{NaClO}$ for $10 \mathrm{~min}$, germinated in distilled water at $25 \pm 1{ }^{\circ} \mathrm{C}$ for 2 days in dark, and seedlings were grown on the illuminating incubator at $25 \pm 1{ }^{\circ} \mathrm{C}$ with a $200 \mu \mathrm{mol}$ $\mathrm{m}^{-2} \cdot \mathrm{s}^{-1}$ intensity at $14 / 10$ photoperiod. Afterwards, the selected seedlings were transferred to the indicated chemicals for the indicated time points.

Arabidopsis (Arabidopsis thaliana) seeds of nia1 (CS6936) and nia2 (CS2355) mutants were obtained from the Arabidopsis Biological Resource Center (available online: http:/ / www.arabidopsis.org/abrc). 
Seeds were sterilized and rinsed at least three times with sterile water, then cultured in $1 / 2$ Murashige and Skoog (MS, pH 5.8) solid medium containing $1 \%(w / v)$ agar and $1 \%(w / v)$ sucrose. Seeds were kept at $4{ }^{\circ} \mathrm{C}$ for 2 days, and then transferred into a growth chamber with $16 / 8$ photoperiod $\left(22 / 18^{\circ} \mathrm{C}\right)$ with a $200 \mu \mathrm{mol} \mathrm{m}{ }^{-2} \cdot \mathrm{s}^{-1}$ irradiation for the indicated time points.

Afterwards, photographs were taken, and the number of emerged lateral roots (LRs; $>1 \mathrm{~mm}$ ) per seedling and the length of lateral roots were determined with Image J software. LR primordia (LRP) per seedling were also observed by root squash preparations and quantified by a light microscope (model Stemi 2000-C; Carl Zeiss, Germany; [5]). Additionally, only the lateral root-inducible segments were used for the subsequent biochemical and molecular analyses.

\subsection{Preparation of $\mathrm{H}_{2}$-Rich Water}

Purified $\mathrm{H}_{2}$ gas $(99.99 \%, v / v)$ generated from a hydrogen gas generator (SHC-300, Saikesaisi Hydrogen Energy Co., Ltd., Ji'nan, China) was bubbled into $1000 \mathrm{~mL}$ distilled water at a rate of $150 \mathrm{~mL} \cdot \mathrm{min}^{-1}$ for $30 \mathrm{~min}$, thus reaching a saturated level. In our experimental conditions, the $\mathrm{H}_{2}$ concentration in above saturated $\mathrm{H}_{2}$-rich water analyzed by gas chromatography (GC) was about $0.78 \mathrm{mM}$ [25]. The working conditions of GC were optimized as detector temperature of thermal conductivity detector (TCD) at $100{ }^{\circ} \mathrm{C}, 5 \AA$ molecular sieve as fixed phase, column temperature at $150{ }^{\circ} \mathrm{C}$, and oven temperature at $60^{\circ} \mathrm{C}$. Nitrogen gas was used as carrier gas and air pressure was $0.2 \mathrm{MPa}$. Afterwards, the corresponding $\mathrm{H}_{2}$-rich water was immediately diluted to the required concentrations of $\mathrm{H}_{2}(0.0078,0.078$, and $0.39 \mathrm{mM})$.

\subsection{Measurement of Endogenous $\mathrm{H}_{2}$}

Endogenous $\mathrm{H}_{2}$ was measured by gas chromatography (GC, 5890C, Nanjing Kejie Technology, Ltd, Nanjing, China) [22,27]. Approximately $0.3 \mathrm{~g}$ of tomato seedlings were homogenized for $1 \mathrm{~min}$, placed them in a vial, and then $7 \mathrm{~mL}$ distilled water, $5 \mu \mathrm{L}$ octanol and $0.5 \mathrm{~mL} 5 \mathrm{M}$ sulphuric acid were added. Afterwards, pure nitrogen gas was bubbled in vial to fully displace the air. After it was capped and shaken immediately for $1 \mathrm{~min}$, the vial was heated at $70^{\circ} \mathrm{C}$ for $1 \mathrm{~h}$ to liberate $\mathrm{H}_{2}$ from plant tissues, and allowed to cool at room temperature before the head-space was analyzed.

\subsection{Detection of Endogenous NO}

The endogenous NO level was monitored by a laser confocal scanning microscopy (LCSM) using the specific NO fluorescent probe 4-amino-5-methylamino-2' ${ }^{\prime} 7^{\prime}$-difluorofluorescein diacetate (DAF-FM DA) $[43,44]$. Tomato root samples were chosen at the indicated time points, and loaded with $10 \mu \mathrm{M}$ DAF-FM DA in $20 \mathrm{mM}$ HEPES/NaOH buffer ( $\mathrm{pH}$ 7.5) for $30 \mathrm{~min}$, then washed with distilled water for three times. All images were visualized by using LSCM (TCS-SP2 system; Leica Lasertechnik $\mathrm{GmbH}$, Heidelberg, Germany). Five individual samples were randomly selected and measured per treatment. All manipulations were performed at $25^{\circ} \mathrm{C}$. We showed $40-\mu \mathrm{m}$-thick sections along $\mathrm{Z}$ stack, and the bright-field (BF) images corresponding to the fluorescent images were shown at the bottom right corners. Fluorescence of NO level in roots was quantified based on 20 overlapping confocal planes of $2 \mu \mathrm{m}$ each using the Leica software.

Endogenous NO production was also quantified by EPR as described previously [22,45,46]. After different treatments, about $0.1 \mathrm{~g}$ tomato seedling roots were crushed with a mortar and pestle, then were incubated in $0.3 \mathrm{~mL}$ of buffer solution (50 mM HEPES, $1 \mathrm{mM} \mathrm{MgCl} 2,1 \mathrm{mM}$ dithiothreitol, $\mathrm{pH}$ 7.6) at room temperature for $2 \mathrm{~min}$. The mixture was added to $0.3 \mathrm{~mL}$ of freshly made $\mathrm{Fe}^{2+}(\mathrm{DETC})_{2}$ solution in dark at room temperature for $2 \mathrm{~min}$. Then, $0.2 \mathrm{~mL}$ of ethyl acetate was added, shaken for $3 \mathrm{~min}$ and centrifuged at $4{ }^{\circ} \mathrm{C}(12,000 \times g)$ for $5 \mathrm{~min}$. EPR was carried out on a Bruker A300 spectrometer (Bruker Instrument, Karlsruhe, Germany) under the following conditions: room temperature; microwave frequency, $9.85 \mathrm{GHz}$; modulation frequency, $100.00 \mathrm{kHz}$, microwave power, $63.49 \mathrm{~mW}$. 


\subsection{Determination of Nitrate Reductase (NR) Activity}

The NR activity was detected spectrophotometrically at $540 \mathrm{~nm}$ according to the previous method [38].

\subsection{RNA Extraction and Real-Time Quantitative RT-PCR (qPCR) Analysis}

Total RNA was extracted from roots using Trizol reagent (Invitrogen, Gaithersburg, MD, USA) according to the manufacturer's instructions. The RNA samples were treated with RNAase-free DNase (TaKaRa Bio, Inc., Dalian, China) to eliminate traces of DNA, and the RNA concentration and quality were detected using the NanoDrop 2000 (Thermo Fisher Scientific, Wilmington, DE, USA). Afterwards, cDNA were synthesized from total RNA $(2 \mu \mathrm{g})$ using an oligo(dT) primer and M-MLV reverse transcriptase (BioTeke, Beijing, China).

Real-time quantitative RT-PCR (qPCR) was performed using a Mastercycler ${ }^{\circledR}$ ep realplex real-time PCR system (Eppendorf, Hamburg, Germany) with TransStart Top Green qPCR SuperMix (TransGen Biotech, Beijing, China). Using the specific primers (Table S1), the relative expression levels of the corresponding genes were normalized to two internal control genes tomato CAC and TIP41. The quantification of the relative transcript levels was calculated by using the $2^{-\Delta \Delta C t}$ method $[47,48]$.

\subsection{Data Analysis}

Where indicated, results are expressed as the means \pm SE of at least three independent experiments with at least three replicates for each. Statistical analysis was performed using SPSS 10.0 software. For statistical analysis, either the $t$-test $(p<0.05)$ or one-way analysis of variance (ANOVA) followed by Duncan's multiple range test $(p<0.05)$, was selected where appropriate.

Supplementary Materials: Supplementary materials can be found at www.mdpi.com/1422-0067/18/10/2084/s1.

Acknowledgments: This work was supported by the Natural Science Foundation of Jiangsu Province (BK20141361), the Fundamental Research Funds for the Central Universities (KYTZ201402), and the Priority Academic Program Development of Jiangsu Higher Education Institutions (PAPD).

Author Contributions: Zeyu Cao, Xingliang Duan designed and refined the research; Zeyu Cao, Xingliang Duan, Ping Yao, and Wenbiao Shen performed research; Zeyu Cao, Ping Yao, Weiti Cui, Dan Cheng, Jing Zhang, Qijiang Jin, Jun Chen, Tianshan Dai, and Wenbiao Shen analyzed data; Zeyu Cao, Xingliang Duan, and Wenbiao Shen wrote the article. All authors read and approved the final manuscript.

Conflicts of Interest: The authors declare no conflict of interest.

\section{Abbreviations}

$\begin{array}{ll}\text { LR } & \text { lateral root } \\ \text { NAA } & \text { 1-naphthyl acetic acid } \\ \text { NPA } & \text { N-1-naphthylphthalamic acid } \\ \text { EPR } & \text { electron paramagnetic resonance } \\ \text { cPTIO } & \text { 2-4-carboxyphenyl-4,4,5,5-tetramethylimidazoline-1-oxyl-3-oxide } \\ \text { NR } & \text { nitrate reductase } \\ \text { NO } & \text { nitric oxide } \\ \text { NOS } & \text { nitric oxide synthetase } \\ \mathrm{H}_{2} & \text { hydrogen gas } \\ \text { GC } & \text { gas chromatography } \\ \text { LSCM } & \text { laser scanning confocal microscopy } \\ \text { NAME } & N^{G} \text {-nitro-L-arginine methyl ester hydrochloride } \\ \text { GSNOR } & \text { S-nitrosoglutathione reductase } \\ \text { Tg } & \text { tungstate }\end{array}$

\section{References}

1. Casimiro, I.; Beeckman, T.; Graham, N.; Bhalerao, R.; Zhang, H.; Casero, P.; Sandberg, G.; Bennett, M.J. Dissecting Arabidopsis lateral root development. Trends Plant Sci. 2003, 8, 165-171. [CrossRef] 
2. Péret, B.; Rybe, B.; Casimiro, I.; Benková, E.; Swarup, R.; Laplaze, L.; Beeckman, T.; Bennett, M.J. Arabidopsis lateral root development: An emerging story. Trends Plant Sci. 2009, 14, 399-408. [CrossRef] [PubMed]

3. Lavenus, J.; Goh, T.; Roberts, I.; Guyomarch, S.; Lucas, M.; Smet, I.D. Lateral root development in Arabidopsis: Fifty shades of auxin. Trends Plant Sci. 2013, 18, 450-458. [CrossRef] [PubMed]

4. Perrine-Walker, F.M.; Jublanc, E. The localization of auxin transporters PIN3 and LAX3 during lateral root development in Arabidopsis thaliana. Biol. Plantarum. 2014, 58, 778-782. [CrossRef]

5. Correa-Aragunde, N.; Graziano, M.; Chevalier, C.; Lamattina, L. Nitric oxide modulates the expression of cell cycle regulatory genes during lateral root formation in tomato. J. Exp. Bot. 2006, 57, 581-588. [CrossRef] [PubMed]

6. Casimiro, I.; Marchant, A.; Bhalerao, R.P.; Beeckman, T.; Dhooge, S.; Swarup, R.; Graham, N.; Inzé, D.; Sandberg, G.; Casero, P.J. Auxin transport promotes Arabidopsis lateral root initiation. Plant Cell 2001, 13, 843-852. [CrossRef] [PubMed]

7. Correa-Aragunde, N.; Graziano, M.; Lamattina, L. Nitric oxide plays a central role in determining lateral root development in tomato. Planta 2004, 218, 900-905. [CrossRef] [PubMed]

8. Lombardo, M.C.; Graziano, M.; Polacco, J.C.; Lamattina, L. Nitric oxide functions as a positive regulator of root hair development. Plant Signal. Behav. 2006, 1, 28-33. [CrossRef]

9. Pagnussat, G.C.; Simontacchi, M.; Puntarulo, S.; Lamattina, L. Nitric oxide is required for root organogenesis. Plant Physiol. 2002, 129, 954-956. [CrossRef] [PubMed]

10. Correa-Aragunde, N.; París, R.; Foresi, N.; Terrile, C.; Casalongué, C.; Lamattina, L. The auxin-nitric oxide highway: A right direction in determining the plant root system. In Gasotransmitters in Plants; Lamattina, L., García-Mata, C., Eds; Springer International Publishing: Cham, Switzerland, 2016; pp. 117-136.

11. Gupta, K.J.; Fernie, A.R.; Kaiser, W.M.; van Dongen, J.T. On the origins of nitric oxide. Trends Plant Sci. 2010, 16, 160-168. [CrossRef] [PubMed]

12. Renwick, G.M.; Giumarro, C.; Siegel, S.M. Hydrogen metabolism in higher plants. Plant Physiol. 1964, 39, 303-306. [CrossRef] [PubMed]

13. Huang, C.S.; Kawamura, T.; Toyoda, Y.; Nakao, A. Recent advances in hydrogen research as a therapeutic medical gas. Free Radic. Res. 2010, 44, 971-982. [CrossRef] [PubMed]

14. Zheng, X.F.; Sun, X.J.; Xia, Z.F. Hydrogen resuscitation, a new cytoprotective approach. Clin. Exp. Pharmacol. Physiol. 2011, 38, 155-163. [CrossRef] [PubMed]

15. Sun, Q.; Cai, J.; Liu, S.; Liu, Y.; Xu, W.; Tao, H.; Sun, X. Hydrogen-rich saline provides protection against hyperoxic lung injury. J. Surg. Res. 2011, 165, 43-49. [CrossRef] [PubMed]

16. Chen, M.; Cui, W.; Zhu, K.; Xie, Y.; Zhang, C.; Shen, W. Hydrogen-rich water alleviates aluminum-induced inhibition of root elongation in alfalfa via decreasing nitric oxide production. J. Hazard. Mater. 2014, 267, 40-47. [CrossRef] [PubMed]

17. Lin, Y.; Zhang, W.; Qi, F.; Cui, W.; Xie, Y.; Shen, W. Hydrogen-rich water regulates cucumber adventitious root development in a heme oxygenase-1/carbon monoxide-dependent manner. J. Plant Physiol. 2014, 171, 1-8. [CrossRef] [PubMed]

18. Rodríguez-Ruiz, M.; Mioto, P.; Palma, J.M.; Corpas, F.J. S-nitrosoglutathione reductase (GSNOR) activity is down-regulated during pepper (Capsicum annuum L.) fruit ripening. Nitric Oxide 2017, 27, 51-55. [CrossRef] [PubMed]

19. Bright, J.; Desikan, R.; Hancock, J.T.; Weir, I.S.; Neill, S.J. ABA-induced NO generation and stomatal closure in Arabidopsis are dependent on $\mathrm{H}_{2} \mathrm{O}_{2}$ synthesis. Plant J. 2006, 45, 113-122. [CrossRef] [PubMed]

20. Lamattina, L.; Garc'1a-Mata, C.; Graziano, M.; Pagnussat, G. Nitric oxide: The versatility of an extensive signal molecule. Annul. Rev. Plant Biol. 2003, 54, 109-136. [CrossRef] [PubMed]

21. Neill, S.J.; Desikan, R.; Hancock, J.T. Nitric oxide signaling in plants. New Phytol. 2003, 159, 11-35. [CrossRef]

22. Xie, Y.; Mao, Y.; Zhang, W.; Lai, D.; Wang, Q.; Shen, W. Reactive oxygen species dependent nitric oxide production contributes to hydrogen promoted stomatal closure in Arabidopsis. Plant Physiol. 2014, 165, 759-773. [CrossRef] [PubMed]

23. Zeng, J.; Zhang, M.; Sun, X. Molecular hydrogen is involved in phytohormone signaling and stress response in plants. PLoS ONE 2013, 8, e71038. [CrossRef] [PubMed]

24. Maimaiti, J.; Zhang, Y.; Yang, J.; Cen, Y.P.; Layzell, D.B.; Peoples, M.; Dong, Z. Isolation and characterization of hydrogen-oxidizing bacteria induced following exposure of soil to hydrogen gas and their impact on plant growth. Environ. Microbiol. 2007, 9, 435-444. [CrossRef] [PubMed] 
25. Xie, Y.; Mao, Y.; Lai, D.; Zhang, W.; Shen, W. H2 enhances Arabidopsis salt tolerance by manipulating ZAT10/12-mediated antioxidant defence and controlling sodium exclusion. PLOS ONE 2012, 7, e49800. [CrossRef] [PubMed]

26. Xu, S.; Zhu, S.S.; Long, J.Y.; Wang, N.; Wang, R.; Shen, W. Hydrogen-rich water alleviates salt stress in rice during seed germination. Plant Soil 2013, 370, 47-57. [CrossRef]

27. Jin, Q.; Zhu, K.; Cui, W.; Xie, Y.; Han, B.; Shen, W. Hydrogen gas acts as a novel bioactive molecule in enhancing plant tolerance to paraquat-induced oxidative stress via the modulation of heme oxygenase-1 signalling system. Plant Cell Environ. 2013, 36, 956-969. [CrossRef] [PubMed]

28. Cui, W.; Gao, C.; Fang, P.; Lin, G.; Shen, W. Alleviation of cadmium toxicity in Medicago sativa by hydrogen-rich water. J. Hazard. Mater. 2013, 260, 715-724. [CrossRef] [PubMed]

29. Cui, W.; Fang, P.; Zhu, K.; Mao, Yu.; Gao, C.; Xie, Y.; Wang, J.; Shen, W.B. Hydrogen-rich water confers plant tolerance to mercury toxicity in alfalfa seedlings. Ecotoxicol. Environ. Saf. 2014, 5, 103-111. [CrossRef] [PubMed]

30. Xu, D.; Cao, H.; Fang, W.; Pan, J.; Chen, J.; Zhang, J.; Shen, W. Linking hydrogen-enhanced rice aluminum tolerance with the reestablishment of GA/ABA balance and miRNA-modulated gene expression: A case study on germination. Ecotoxicol. Environ. Saf. 2017, 145, 303-312. [CrossRef] [PubMed]

31. De Smet, I.; Signora, L.; Beeckman, T.; Inzé, D.; Foyer, C.H.; Zhang, H. An abscisic acid-sensitive checkpoint in lateral root development of Arabidopsis. Plant J. 2003, 33, 543-555. [CrossRef] [PubMed]

32. Beligni, M.V.; Lamattina, L. Nitric oxide stimulates seed germination and de-etiolation, and inhibits hypocotyl elongation, three light-inducible responses in plants. Planta 2000, 210, 215-221. [CrossRef] [PubMed]

33. Stohr, C.; Stremlau, S. Formation and possible roles of nitric oxide in plant roots. J. Exp. Bot. 2006, 57, 463-470. [CrossRef] [PubMed]

34. Besson-Bard, A.; Pugin, A.; Wendehenne, D. New insights into nitric oxide signaling in plants. Annul. Rev. Plant Biol. 2008, 59, 21-39. [CrossRef] [PubMed]

35. Yu, M.; Lamattina, L.; Spoel, S.H.; Loake, G.J. Nitric oxide function in plant biology: A redox cue in deconvolution. New Phytol. 2014, 202, 1142-1156. [CrossRef] [PubMed]

36. Sakihama, Y.; Nakamura, S.; Yamasaki, H. Nitric oxide production mediated by nitrate reductase in the green alga Chlamydomonas reinhardtii: an alternative NO production pathway in photosynthetic organisms. Plant Cell Physiol. 2002, 43, 290-297. [CrossRef] [PubMed]

37. Yamasaki, H.; Sakihama, Y. Simultaneous production of nitric oxide and peroxynitrite by plant nitrate reductase: In vitro evidence for the NR-dependent formation of active nitrogen species. FEBS Lett. 2000, 468, 89-92. [CrossRef]

38. Zhao, M.; Chen, L.; Zhang, L.; Zhang, W. Nitric reductase-dependent nitric oxide production is involved in cold acclimation and freezing tolerance in Arabidopsis. Plant Physiol. 2009, 151, 755-767. [CrossRef] [PubMed]

39. Sun, H.; Li, J.; Song, W.; Tao, J.; Huang, S.; Chen, S.; Zhang, Y. Nitric oxide generated by nitrate reductase increases nitrogen uptake capacity by inducing lateral root formation and inorganic nitrogen uptake under partial nitrate nutrition in rice. J. Exp. Bot. 2015, 66, 2449-2459. [CrossRef] [PubMed]

40. Perrine-Walker, F.M.; Gartner, E.; Hocart, C.H.; Becker, A.; Rolfe, B.G. Rhizobium-initiated rice growth inhibition caused by nitric oxide accumulation. Mol. Plant Micorbe Interact. 2007, 20, 283-292. [CrossRef] [PubMed]

41. Zhu, Y.; Liao, W.; Niu, L.; Wang, M.; Ma, Z. Nitric oxide is involved in hydrogen gas-induced cell cycle activation during adventitious root formation in cucumber. BMC Plant Biol. 2016, 16, 146. [CrossRef] [PubMed]

42. Himanen, K.; Boucheron, E.; Vanneste, S.; de Almeida Engler, J.; Inzé, D.; Beeckman, T. Auxin-mediated cell cycle activation during early lateral root initiation. Plant Cell 2002, 14, 2339-2351. [CrossRef] [PubMed]

43. He, J.; Ma, X.; Zhang, Y.; Sun, T.; Xu, F.; Chen, Y.; Liu, X.; Yue, M. Role and interrelationship of Ga protein, hydrogen peroxide, and nitric oxide in ultraviolet B-induced stomatal closure in Arabidopsis leaves. Plant Physiol. 2013, 161, 1570-1583. [CrossRef] [PubMed]

44. Xie, Y.; Mao, Y.; Lai, D.; Zhang, W.; Zheng, T.; Shen, W. Roles of NIA/NR/ NOA1-dependent nitric oxide production and HY1 expression in the modulation of Arabidopsis salt tolerance. J. Exp. Bot. 2013, 64, 3045-3060. [CrossRef] [PubMed] 
45. Xu, Y.; Cao, Y.; Guo, P.; Tao, Y.; Zhao, B. Detection of nitric oxide in plants by electron spin resonance. Phytopathology 2004, 94, 402-407. [CrossRef] [PubMed]

46. Sun, A.Z.; Nie, S.J.; Xing, D. Nitric oxide-mediated maintenance of redox homeostasis contributes to NPR1-dependent plant innate immunity triggered by lipopolysaccharides. Plant Physiol. 2012, 160, 1081-1096. [CrossRef] [PubMed]

47. Expósito-Rodríguez, M.; Borges, A.A.; Borges-Pérez, A.; Pérez, J.A. Selection of internal control genes for quantitative real-time RT-PCR studies during tomato development process. BMC Plant Boil. 2008, 8, 131. [CrossRef] [PubMed]

48. Vandesompele, J.; de Preter, K.; Pattyn, F.; Poppe, B.; van Roy, N.; De Paepe, A.; Speleman, F. Accurate normalization of real-time quantitative RT-PCR data by geometric averaging of multiple internal control genes. Genome Biol. 2002, 3, 1-12. [CrossRef]

2017 by the authors. Licensee MDPI, Basel, Switzerland. This article is an open access article distributed under the terms and conditions of the Creative Commons Attribution (CC BY) license (http://creativecommons.org/licenses/by/4.0/). 